\title{
Pressure Ulcers and Prolonged Hospital Stay in Hip Fracture Patients Affected by Time-to-Surgery
}

\author{
Leonard M.F. Rademakers', Tryfon Vainas², Stefan W.A.M. van Zutphen³, Peter R.G. Brink ${ }^{4}$, \\ Sven $\mathrm{H}$. van Helden ${ }^{4}$
}

\begin{abstract}
Background: Hip fractures are associated with high morbidity. Pressure ulcer formation after hip surgery is often related to delayed patient mobilization. The objectives of this study were to determine whether time-to-surgery affects development of pressure ulcers postoperatively and, thus, length of hospital stay.

Patients and Methods: We performed a retrospective analysis of consecutive hip fracture patients, aged 60 years and above, who underwent surgery between 1995 and 2001. The primary outcome was in-hospital development of pressure ulcers. The secondary outcome measure was the overall length of hospital stay. Analyses were adjusted for relevant confounders. Results: Of the 722 patients enrolled, 488 patients $(68 \%)$ received surgery at $12 \mathrm{~h}$ after admission. Approximately $30 \%(n=214)$ developed pressure ulcers during admission, whilst $19 \%$ of patients operated within $12 \mathrm{~h}$ of admission developed pressure ulcers. Time-to-surgery was an independent predictor of both development of pressure ulcers $(O R=1.7,95 \%$ confidence interval $[\mathrm{Cl}]=1.2-2.6 ; \mathrm{p}=0.008)$ and length of hospital stay (11.3 vs 13.3 days in the early and the late surgery group, respectively, $p=0.050$ ). Furthermore, development of pressure ulcers was associated with prolonged postoperative hospital stay (19.5 vs 11.1 days for patients with and without pressure ulcers, respectively, $p=0.001$ )
\end{abstract}

\footnotetext{
'Department of Cardiothoracic Surgery, Maastricht University Hospital, Maastricht, The Netherlands,

${ }^{2}$ Department of Surgery, Maastricht University Hospital, Maastricht, The Netherlands,

${ }^{3}$ Department of Surgery, TweeSteden Hospital, Tilburg, The Netherlands,

${ }^{4}$ Department of Traumatology, Maastricht University Hospital, Maastricht, The Netherlands.
}

Investigation performed at the Department of Traumatology, Maastricht University Hospital, Maastricht, The Netherlands.

Received: December 12, 2006; revision accepted: April 21, 2007; Published Online: May 30, 2007
Interpretation: In hip fracture patients, time-to-surgery was an independent predictor of both postoperative pressure ulcer development and prolonged hospital stay. These data suggest that the implementation of an early surgery protocol following admission for hip fractures may reduce both the postoperative complications and overall hospital stay.

\section{Key Words}

Soft tissue injuries and infection - Fracture care · Hip fracture - Fractures of the proximal .

Femur - Hip fractures - Orthopedic trauma .

Osteosynthesis

Eur J Trauma Emerg Surg 2007;33:238-44

DOI $10.1007 / \mathrm{s} 00068-007-6212-8$

\section{Introduction}

Hip fractures occur frequently in the elderly. The global incidence of hip fractures in patients is expected to increase to about 6.3 million by the year 2050 [1]. Among all fracture types, fractures of the hip carry the most serious clinical consequences. Complications may arise from the fracture itself, the surgical procedure or medical comorbidities. Hip fractures are often associated with a poor functional outcome [2, 3]. Almost $45 \%$ of patients will suffer from new permanent ADL 
deficits after hip fracture $[4,5]$ and approximately $15 \%$ will require prolonged nursing home care $[4,6]$. With the ageing population, the number of patients at risk for hip fractures are likely to increase. A significant number of patients with hip fractures are malnourished and all are bed bound in the perioperative phase. Development of pressure ulcers is one of the frequent complications of hip surgery associated with delayed patient mobilization [7, 8]. Patients with pressure ulcers following hip fractures require significantly more nursing care, lengthy hospital stay, increased hospital costs and are at higher risk of long term nursing home stay and utilize more health care resources following discharge compared to patients without pressure ulcers [9]. The aim of our study was to identify (modifiable) factors associated with the development of pressure ulcers after surgery for hip fractures and identify parameters related to prolonged hospital stay after surgery.

\section{Patients and Methods}

A retrospective analysis of all hip fracture patients treated in a level one trauma centre, recruiting all the fractures in the area was conducted. Patient and fracture characteristics were analyzed from the hospital records. These included age, sex, ASA (American Society of Anaesthesiologists) classification, type of fracture, date and time of admission, time-to-surgery (i.e., time between admission and operation), type and duration of surgery, type of anaesthesia, time to mobilization (i.e., time from surgery to first time out of bed) and duration of total and postoperative hospital stay. In addition, information regarding pre-existing medical conditions as well as postoperative complications was retrieved from the records. Associated medical comorbidities included hypertension (diagnosed as a systolic blood pressure $>160 \mathrm{mmHg}$ and/or use of antihypertensive medication), cardiac disease (i.e., coronary artery disease, congestive heart failure, valvular heart disease, and cardiac arrhythmias, diagnosed by the attending physician according to guidelines issued from the European Society of Cardiology), diabetes mellitus (fasting glucose level $>7 \mathrm{mmol} / \mathrm{l}$ and/or use of antiglycemic medication/insulin) chronic obstructive pulmonary disease (diagnosed by the attending physician), stroke or transient ischemic attacks (as diagnosed by the attending physician), renal dysfunction (diagnosed by attending physician), and current or past malignancy (diagnosed by attending physician). Postoperative complications included myocardial infarction, con- gestive heart failure, pulmonary embolism, urinary tract infection, pneumonia, sepsis, stroke, dislocation of hip implant, wound infection, and bleeding requiring exploration.

The development of pressure ulcers was assessed by both attending physicians and nurses, according to EPUAP guidelines for pressure ulcers [10]. Skin lesions showing at least partial or total thickness skin loss involving epidermis, dermis or both (Grade II or higher according to EPUAP guidelines) were classified as pressure ulcers.

Exclusion criteria were age $<60$ years, (multiple) high energy trauma (defined as a fall from higher than ground level, or road traffic accidents), initial conservative treatment, inter hospital transfer, presence of pressure ulcers at admission, pathological fractures and recurrent fractures. Between the 1 January 1995 and 31 July 2001, 1,048 patients with hip fractures were treated. Of these, 326 were excluded from the study by applying the above criteria.

\section{Statistical Methods}

Results were first analyzed by descriptive statistics. Differences between groups were assessed by the Chisquare test for dichotomous data and by Student's t test or the Mann-Whitney U test for continuous data. The influence of operative delay on postoperative outcome and the relation between pressure ulcer development and relevant risk factors were assessed using univariate logistic analyses. All variables that showed a trend towards association with operative delay or the development of pressure ulcers (i.e., a $p$ value $<0.10$ ) were entered as independent variables in a multivariate logistic regression model with pressure ulcers as the dependent outcome variable. A probability value of $<0.05$ was considered statistically significant.

\section{Results}

In this study, 722 patients [551 (76.3\%) women] with hip fractures were entered. The median age of the overall population was 82.2 years (76.9-87.5). A significant proportion of the cohort had co-morbid conditions at inclusion such as hypertension, cardiac disease, diabetes, COPD, stroke, end-stage renal disease or malignancy (Table 1). Out of the overall sample $43.2 \%(n=312)$ was classified as ASA class III or IV.

Approximately $65 \%$ of patients $(n=467)$ sustained femoral neck fracture. The remaining 35\% $(\mathrm{n}=255)$ suffered fracture of the trochanteric region. The majority of patients $(54 \%, \mathrm{n}=391)$ received 
Table 1. Preoperative patient characteristics of 722 patients with early and delayed $\left(>12 \mathrm{~h}\right.$ ) time-to-surgery. Data are analyzed with $\chi^{2}$-test, unless otherwise specified.

\begin{tabular}{|c|c|c|c|c|}
\hline Characteristic & Total population & $\begin{array}{l}\text { Surgery }<12 \mathrm{~h} \\
\text { after admission }\end{array}$ & $\begin{array}{l}\text { Surgery } \geq 12 \mathrm{~h} \\
\text { after admission }\end{array}$ & $\mathrm{p}$ \\
\hline Patients, \% (N) & & & & $0.408^{\mathrm{a}}$ \\
\hline Women & $76.3(551)$ & $78.2(183)$ & $75.4(368)$ & \\
\hline Men & $23.7(171)$ & $21.8(51)$ & $24.6(120)$ & \\
\hline Age, mean (IQR) & $82.2(76.9-87.5)$ & $81.9(76.2-87.8)$ & $82.3(77.1-87.4)$ & 0.62 \\
\hline \multicolumn{5}{|c|}{ Medical history ${ }^{\mathrm{b}}, \%(\mathrm{~N})$} \\
\hline Hypertension & $38.9(281)$ & $34.2(80)$ & $41.2(201)$ & 0.071 \\
\hline Cardiac disease $^{c}$ & $47.8(345)$ & $36.3(85)$ & $53.3(260)$ & 0.001 \\
\hline Diabetes & $17.2(124)$ & $13.2(31)$ & $19.1(93)$ & 0.053 \\
\hline COPD & $18.1(131)$ & $14.1(33)$ & $20.1(98)$ & 0.051 \\
\hline Stroke & $19.3(139)$ & $16.7(39)$ & $20.5(100)$ & 0.223 \\
\hline ESRD $^{d}$ & $1.8(13)$ & $1.7(4)$ & $1.8(9)$ & 0.899 \\
\hline Cancer $^{\mathrm{e}}$ & $19.0(137)$ & $17.5(41)$ & $19.7(96)$ & 0.491 \\
\hline ASA class, \% (N) & & & & $0.001^{f}$ \\
\hline I/II & $56.8(410)$ & $65.8(154)$ & $52.2(256)$ & 0.24 \\
\hline III/IV & $43.2(312)$ & $34.2(80)$ & $47.5(232)$ & 0.012 \\
\hline
\end{tabular}

${ }^{\text {a }}$ Comparison distribution of sex within the early and late surgery group

${ }^{\mathrm{b}}$ Medical history have been determined from chart review

${ }^{\mathrm{c}}$ Includes a history of ischemic coronary artery disease, valvular disease, congestive heart failure or arrhythmia

${ }^{\mathrm{d}}$ End-stage renal disease requiring dialysis

${ }^{\mathrm{e}}$ History of any type of malignancy

${ }^{f}$ Comparison distribution of ASA class I/II and III/IV within early and late surgery group, Mann-Whitney U test

Table 2. Operative data of 722 patients treated for hip fractures. Data are analyzed with $\chi^{2}$-test.

\begin{tabular}{|c|c|c|c|c|}
\hline Characteristic & Total population & $\begin{array}{l}\text { Surgery }<12 \mathrm{~h} \\
\text { after admission }\end{array}$ & $\begin{array}{l}\text { Surgery } \geq 12 \mathrm{~h} \\
\text { after admission }\end{array}$ & $\mathbf{p}$ \\
\hline Type of fracture, \% (N) & & & & $0.054^{\mathrm{a}}$ \\
\hline Medial neck & $58.3(421)$ & $53.0(124)$ & $61.1(298)$ & 0.035 \\
\hline Lateral neck & $6.4(46)$ & $6.8(16)$ & $6.1(30)$ & 0.712 \\
\hline Pertrochanteric & $33.0(238)$ & $38.9(91)$ & $29.9(146)$ & 0.015 \\
\hline Subtrochanteric & $2.4(17)$ & $1.3(3)$ & $2.9(14)$ & 0.191 \\
\hline Technique, \% (N) & & & & $0.611^{\mathrm{b}}$ \\
\hline Dynamic hip screw & $14.1(102)$ & $16.7(39)$ & $12.9(63)$ & 0.035 \\
\hline (Hemi)Arthroplasty & $54.2(391)$ & $47.9(112)$ & $57.2(279)$ & 0.019 \\
\hline Gamma nail & $25.8(186)$ & $28.6(67)$ & $24.4(119)$ & 0.488 \\
\hline 3 Canulated screws & $6.0(43)$ & $6.8(16)$ & $5.5(27)$ & 0.222 \\
\hline Anaesthesia, \% (N) & & & & $0.665^{\mathrm{c}}$ \\
\hline General & $40.0(289)$ & $38.9(91)$ & $40.6(198)$ & \\
\hline Spinal & $60.0(433)$ & $61.1(143)$ & $59.4(290)$ & \\
\hline
\end{tabular}

${ }^{\text {a }}$ Comparison distribution entire set of fracture types between early and late surgery group

${ }^{b}$ Comparison distribution entire set of surgical techniques between early and late surgery group

${ }^{c}$ Comparison distribution entire set of anaesthesia types between early and late surgery group

total or hemi-arthroplasty. Femoral head preserving treatment was chosen in $46 \%(\mathrm{n}=331)$ of the cohort. In these, three cannulated screws were used for the treatment of femoral neck fractures and one gamma nail for the majority of (sub- and per-) tro- chanteric fractures after closed reduction of the fracture had been achieved. Sixty percent of all procedures were performed under spinal anaesthesia (Table 2). The median (IQR) time of surgery was 60 (50-75) min. 
Table 3. Complications after surgical treatment for hip fractures. Data are analyzed with $\chi^{2}$-test.

\begin{tabular}{|c|c|c|c|c|}
\hline & $\begin{array}{l}\text { Total population } \\
(\mathrm{N}=722)\end{array}$ & $\begin{array}{l}\text { Surgery }<12 \mathrm{~h} \text { after } \\
\text { admission }(\mathrm{N}=234)\end{array}$ & $\begin{array}{l}\text { Surgery } \geq 12 \mathrm{~h} \text { after } \\
\text { admission }(\mathrm{N}=488)\end{array}$ & $\mathrm{p}$ \\
\hline \multicolumn{5}{|l|}{ Complications, \% (N) } \\
\hline \multicolumn{5}{|l|}{ Pressure ulcers } \\
\hline Total & $29.6(214)$ & $19.2(45)$ & $34.6(169)$ & 0.001 \\
\hline Grade II & $27.6(199)$ & $18.1(43)$ & $32.3(156)$ & 0.001 \\
\hline Grade III/IV & $2.1(15)$ & $0.8(2)$ & $2.7(13)$ & 0.001 \\
\hline Myocardial infarction & $0.8(6)$ & $0.4(1)$ & $1.0(5)$ & 0.408 \\
\hline Congestive heart failure & $6.1(44)$ & $3.8(9)$ & $7.2(35)$ & 0.081 \\
\hline Pulmonary embolism & $1.2(9)$ & $1.3(3)$ & $1.2(6)$ & 0.953 \\
\hline Urinary tract infection & $19.5(141)$ & $14.5(34)$ & $21.9(107)$ & 0.019 \\
\hline Dislocation hip implant & $5.5(40)$ & $4.3(10)$ & $6.1(30)$ & 0.303 \\
\hline Cerebrovascular accident & $2.4(17)$ & $2.6(6)$ & $2.3(11)$ & 0.797 \\
\hline Wound infection & $3.3(24)$ & $3.4(8)$ & $3.3(16)$ & 0.922 \\
\hline Pneumonia & $6.1(44)$ & $5.1(12)$ & $6.6(32)$ & 0.453 \\
\hline Sepsis & $1.4(10)$ & $0.9(2)$ & $1.6(8)$ & 0.399 \\
\hline Surgical bleeding & $1.4(10)$ & $1.7(4)$ & $1.2(6)$ & 0.606 \\
\hline In-hospital mortality & $7.8(56)$ & $8.0(39)$ & $7.3(17)$ & 0.733 \\
\hline
\end{tabular}

Approximately $70 \%$ of the total sample underwent surgery within $24 \mathrm{~h}$ from admission. One-third of the patients were operated within $12 \mathrm{~h}$. The median (IQR) time-to-surgery was 19.3 (9.0-27.7) h. Cardiac co-morbidities and high ASA class were related to prolonged time-to-surgery $(\mathrm{p}<0.05)$ whereas hypertension, diabetes and chronic obstructive pulmonary disease showed a trend towards association $(\mathrm{p}<0.10)$ with longer time-to-surgery (Table 1).

Postoperatively, a significant proportion of patients developed complications. Approximately $8 \%$ of patients died during admission. Infectious complications (19.5\% urinary tract infections, $3.3 \%$ wound infections and $6.1 \%$ pneumonias) occurred in $29 \%(\mathrm{n}=209)$ of the patients. Approximately $30 \%(n=214)$ of the overall sample developed a pressure ulcer during admission (Table 3).

Patients with severe pre-operative co-morbidities, diabetes, end-stage renal disease, hypertension and cardiac co-morbidity, were more likely to develop pressure ulcers $(\mathrm{OR}=4.70,95 \%$ CI 3.3-6.6, $\mathrm{p}=0.001$; Table 4). Type of osteosynthesis, postoperative pneumonia, postoperative urinary tract infection, and postoperative hip dislocation were significantly related to the development of pressure ulcers (Table 4). The incidence of pressure ulcers was reduced with early postoperative mobilization (within 2 days from surgery) $(\mathrm{OR}=1.46,95 \%$ CI 1.1-2.0, $\mathrm{p}=0.025$; Table 4$)$.

Time-to-surgery was a significant determinant of postoperative development of pressure ulcers. The median (IQR) time-to-surgery was $23.1(14.4-42.3) \mathrm{h}$ for the patients who developed pressure ulcers postoperatively vs 17.5 (8.4-24.8) $\mathrm{h}$ for the patients who did not (Mann-Whitney U test, $\mathrm{p}=0.001$ ). In approximately $1 / 3 \mathrm{rd}$ and $2 / 3 \mathrm{rd}$ of the patients surgery was performed within $12 \mathrm{~h}$ and $24 \mathrm{~h}$ of admission, respectively. Both patients receiving surgery after $24 \mathrm{~h}$ of admission $(\mathrm{OR}=2.1,95 \%$ CI $1.5-3.0, \mathrm{p}=0.001)$ and patients receiving surgery after $12 \mathrm{~h}$ of admission $(\mathrm{OR}=2.2$, 95\% CI 1.5-3.2, p = 0.001) were more likely to develop pressure ulcers postoperatively (Table 4).

Since major co-morbidities were related to both time-to-surgery and postoperative development of pressure ulcers, multivariate logistic regression models were constructed to study this relation. In the multivariate analysis, diabetes, postoperative urinary tract infection, postoperative hip dislocation, high ASA class and time-to-surgery $>12 \mathrm{~h}$, were confirmed as independent predictors of postoperative development of pressure ulcers (Table 5).

Both time-to-surgery and the development of pressure ulcers were associated with prolonged postoperative length of hospital stay. The median (IQR) postoperative length of hospital stay was 19.5 (13.2$35.3)$ and 11.1 (6.6-17.2) days for patients with and without postoperative pressure ulcers, respectively (Mann-Whitney U test, $\mathrm{p}=0.001$ ). The median (IQR) length of postoperative hospital stay was 13.3 (7.6$22.3)$ and 11.3 (7.4-18.7) days in the late and early surgery group, respectively (Mann-Whitney U test, $\mathrm{p}=0.050)$. 
Table 4. Univariate predictors for postoperative development of pressure ulcers.

\begin{tabular}{|c|c|c|c|c|}
\hline \multirow[t]{2}{*}{ Covariate, \% (N) } & \multicolumn{4}{|c|}{ Univariate } \\
\hline & Pressure ulcers & No pressure ulcers & OR $(95 \% \mathrm{CI})$ & $\mathrm{p}$ \\
\hline Hypertension & $43.5(93)$ & $37.0(188)$ & $1.31(0.95-1.81)$ & 0.105 \\
\hline Cardiac co-morbidity $^{\mathrm{a}}$ & $58.4(125)$ & $43.3(220)$ & $1.84(1.33-2.54)$ & 0.001 \\
\hline $\mathrm{ESRD}^{\mathrm{b}}$ & $3.7(8)$ & $1.0(5)$ & $3.91(1.26-12.08)$ & 0.018 \\
\hline Diabetes & $28.9(60)$ & $12.6(64)$ & $2.70(1.82-4.02)$ & 0.001 \\
\hline ASA class III/IV & $69.2(148)$ & $32.3(164)$ & $4.70(3.33-6.64)$ & 0.001 \\
\hline Time-to-surgery $>12 \mathrm{~h}$ & $79.0(169)$ & $62.8(319)$ & $2.23(1.53-3.24)$ & 0.001 \\
\hline Time-to-surgery $>24 \mathrm{~h}$ & $44.9(96)$ & $27.8(141)$ & $2.12(1.52-2.95)$ & 0.001 \\
\hline Technique & & & $0.86(0.73-1.01)$ & $0.058^{\mathrm{C}}$ \\
\hline Arthroplasty & $58.4(125)$ & $52.4(266)$ & $1.28(0.93-1.77)$ & 0.137 \\
\hline DHS & $16.4(35)$ & $13.2(67)$ & $1.29(0.83-2.01)$ & 0.266 \\
\hline Cannulated screws & $1.9(4)$ & $7.8(39)$ & $0.23(0.08-0.65)$ & 0.006 \\
\hline c-Nail & $23.4(50)$ & $26.8(136)$ & $0.83(0.58-1.21)$ & 0.339 \\
\hline Commencement of mobilization $>2$ days & $53.1(110 / 207)$ & $43.8(208 / 475)$ & $1.46(1.05-2.02)$ & 0.025 \\
\hline Postoperative UTI ${ }^{d}$ & $30.4(65)$ & $15.0(76)$ & $2.48(1.70-3.63)$ & 0.001 \\
\hline Postoperative pneumonia & $8.9(19)$ & $4.9(25)$ & $1.88(1.01-3.50)$ & 0.045 \\
\hline Postoperative dislocation implant & $11.2(24)$ & $3.1(16)$ & $3.88(2.02-7.47)$ & 0.001 \\
\hline
\end{tabular}

${ }^{a}$ A history of ischemic coronary artery disease, valvular disease, congestive heart failure or arrhythmia

${ }^{\mathrm{b}}$ End-stage renal disease

${ }^{c}$ Comparison distribution entire set of surgical techniques between pressure ulcer and non-pressure ulcer group

${ }^{\mathrm{d}}$ Urinary tract infection

Table 5. Multivariate logistic regression analysis demonstrating the independent effect of diabetes, urinary tract infection, postoperative hip dislocation, ASA classification and time-to-surgery $>12 \mathrm{~h}$, on the postoperative development of pressure ulcers.

\begin{tabular}{llll}
\hline $\begin{array}{l}\text { Independent } \\
\text { covariates }\end{array}$ & B & OR (95\% CI) & P \\
\hline Diabetes & 0.530 & $1.698(1.082-2.655)$ & 0.021 \\
Urinary tract infection & 0.625 & $1.869(1.224-2.853)$ & 0.004 \\
Postoperative hip dislocation & 0.983 & $2.672(1.278-5.587)$ & 0.009 \\
ASA class III/IV & 1.434 & $4.193(2.882-6.102)$ & 0.001 \\
Time-to-surgery > 12 h & 0.557 & $1.745(1.154-2.640)$ & 0.008 \\
\hline
\end{tabular}

The potential confounders hypertension, cardiac co-morbidity, end-stage renal disease, type of osteosynthesis, delayed commencement of mobilization ( $>2$ days), and postoperative pneumonia were excluded from the analysis

\section{Discussion}

In this study, approximately $30 \%$ of patients with hip fractures developed pressure ulcers postoperatively. Time-to-surgery was an independent predictor of postoperative development of pressure ulcers whilst the total length of hospital stay was related to both time-tosurgery and postoperative pressure ulcer development.

The reported occurrence of pressure ulcers in patients with hip fractures varies between $10 \%$ and $50 \%$ and depends on patient characteristics and the defining criteria [11]. The prevalence of pressure ulcers (grade I and II according to EPUAP) in a recently published series of elderly patients with hip fractures was approximated at 50\% [12].

Several authors studied the effect of surgical delay on postoperative complications, namely mortality, and length of hospital stay in patients with hip fractures. In general, small sample studies $[13,14]$ or studies with a retrospective design [15-17] demonstrated an association between time-to-surgery and mortality. This association has not been verified by recent prospective analyses $[18,19]$. Nevertheless, early surgery may be beneficial in patients with good general health and a high pre-fracture level of activity [14, 20]. Early surgery may offer benefits in terms of shortened length of hospital stay [19, 21, 22], which, in turn, may prevent postoperative complications [19, 23-25]. Delay in surgery may contribute to the development of pressure ulcers. Indeed recently, several authors demonstrated that surgical delay might be an independent predictor of pressure ulcer development [7, 9, 26, 27]. However, others refuted this $[14,16,23,28]$. This could be related to the variation in the definition of early and late surgeries used by different authors. The cut-off point for delayed surgery varied between $12 \mathrm{~h}$ and 4 days, which might hamper comparison of different studies. Nevertheless, our data demonstrated that time-to-surgery is a 
significant determinant of pressure ulcer development, regardless of chosen cut-off point. However, in our patient group time-to-surgery was also related to major co-morbidities, probably reflecting the time needed to prepare these patients for surgery. By using multivariate logistic regression models, we demonstrated that time-to-surgery was independently associated with postoperative pressure ulcer development, as surgery after $12 \mathrm{~h}$ of admission was significantly related to pressure ulcer development. When patients with ASA class I/II or III/IV were analyzed separately, the association between time-to-surgery and pressure ulcer development persisted. Our data demonstrated that major co-morbidities (i.e., cardiac, pulmonary, renal) are a risk factor for development of pressure ulcers on their own right and suggested that prolonged waiting for surgery exposed these patients to an additional risk for postoperative pressure ulcer development. Therefore, high risk patients should be worked up for surgery as early as possible to avoid the additional risk associated with prolonged time-to-surgery per se.

In agreement with others $[29,30]$, our data showed that development of pressure ulcers was significantly related to prolonged length of hospital stay. Therefore, prevention of surgical delay may decrease morbidity and shorten hospitalization for these patients. Considering the increasing age of the general population, and the increasing number of hip fractures in the near future $[1,31]$, implementation of a fast track surgery protocol for patients with hip fractures might prevent complications and decrease hospitalization costs.

Using risk assessment scales, several attempts have been made to identify patients at risk for pressure ulcer development. In view of the complex nature of the process of pressure ulcer development, a great number of potential risk factors have been identified [32] and this has led to difficulties in developing a simple and reliable risk assessment model [33]. To reduce the incidence of pressure ulcers, patients at risk should be placed on low-pressure support systems from arrival at hospital until mobility is restored $[8,34,35]$ However, the clinical and economic effect of these support systems has yet to be proven in properly designed clinical trials [36]. Nutrition plays an important role in the wound-healing process. Protein energy malnutrition is seen more often in elderly patients with hip fractures compared with age-matched control subjects [37-40]. Protein malnutrition is an important determinant of pressure ulcers and infectious complications [33, 41]. Any intervention aimed at restoring protein and energy balances may result in reduced complication rates. Recently, Eneroth and colleagues [38] showed in a prospective randomized trial that protein and energy supplementation resulted in a significant decrease of infectious complications after hip fracture. It remains to be seen whether an identical intervention is efficacious in the prevention of postoperative pressure ulcer development.

There are some limitations to this study that should be considered. Obviously, the retrospective design of the study calls for caution in the interpretation of the results. However, the shear size of the analyzed cohort and the completeness of the clinical data support a likely association between delay in surgery and postoperative development of pressure ulcers. Our data showed that other comorbidities contributing to pressure ulcer development were also related to the study outcome. Although multivariate regression analyses identified prolonged time-to-surgery as an independent predictor for pressure ulcer development, it must be stressed that this statistical analysis can only adjust for those factors measured and included in the model. Time-to-surgery might be correlated closely to an unknown factor. If so, time-to-surgery would be an indirect predictor of pressure ulcer development instead of a direct, causal factor.

In conclusion, prevention of pressure ulcer development using simple measures such as reducing the time-to-surgery, nutritional support and low-pressure support systems should become the standard of care for patients admitted with hip fractures. Particularly high risk patients should be worked up for surgery as soon as possible to avoid the additional risk associated with prolonged time-to-surgery per se. Implementation of this policy could improve clinical outcome and reduce the overall costs in the treatment of hip fracture patients.

\section{References}

1. Melton $\sqcup$ 3rd. Hip fractures: a worldwide problem today and tomorrow. Bone 1993;14:S1-8.

2. Magaziner J, Hawkes W, Hebel JR, Zimmerman SI, Fox KM, Dolan M, Felsenthal G, Kenzora J. Recovery from hip fracture in eight areas of function. J Gerontol A Biol Sci Med Sci 2000;55:M498-507.

3. Magaziner J, Simonsick EM, Kashner TM, Hebel JR, Kenzora JE. Predictors of functional recovery one year following hospital discharge for hip fracture: a prospective study. J Gerontol 1990;45:M101-7.

4. Braithwaite RS, Col NF, Wong JB. Estimating hip fracture morbidity, mortality and costs. J Am Geriatr Soc 2003;51:364-70.

5. Cree M, Carriere KC, Soskolne CL, Suarez-Almazor M. Functional dependence after hip fracture. Am J Phys Med Rehabil 2001;80:736-43.

6. Wiktorowicz ME, Goeree R, Papaioannou A, Adachi JD, Papadimitropoulos E. Economic implications of hip fracture: health 
service use, institutional care and cost in Canada. Osteoporos Int 2001;12:271-8.

7. Grimes JP, Gregory PM, Noveck H, Butler MS, Carson JL. The effects of time-to-surgery on mortality and morbidity in patients following hip fracture. Am J Med 2002;112:702-9.

8. Versluysen M. How elderly patients with femoral fracture develop pressure sores in hospital. Br Med J (Clin Res Ed) 1986;292:1311-3.

9. Baumgarten M, Margolis D, Berlin JA, Strom BL, Garino J, Kagan $\mathrm{SH}$, Kavesh W, Carson JL. Risk factors for pressure ulcers among elderly hip fracture patients. Wound Repair Regen 2003;11:96103.

10. EPUAP. Guidelines on treatment of pressure ulcers. Epuap Rev 1999;1:31-33.

11. Beaupre LA, Jones CA, Saunders LD, Johnston DW, Buckingham J, Majumdar SR. Best practices for elderly hip fracture patients. A systematic overview of the evidence. J Gen Intern Med 2005;20:1019-25.

12. Houwing R, Rozendaal M, Wouters-Wesseling W, Buskens E, Keller P, Haalboom J. Pressure ulcer risk in hip fracture patients. Acta Orthop Scand 2004;75:390-3.

13. Stephens JG, Schenk WG Jr. Early management of the fractured hip. Am J Surg 1959;97:660-2.

14. Zuckerman JD, Skovron ML, Koval KJ, Aharonoff G, Frankel VH. Postoperative complications and mortality associated with operative delay in older patients who have a fracture of the hip. J Bone Joint Surg Am 1995;77:1551-6.

15. Dorotka R, Schoechtner H, Buchinger W. The influence of immediate surgical treatment of proximal femoral fractures on mortality and quality of life. Operation within six hours of the fracture versus later than six hours. J Bone Joint Surg $\mathrm{Br}$ 2003;85:1107-13.

16. Gdalevich $M$, Cohen D, Yosef D, Tauber C. Morbidity and mortality after hip fracture: the impact of operative delay. Arch Orthop Trauma Surg 2004;124:334-40.

17. Weller I, Wai EK, Jaglal S, Kreder HJ. The effect of hospital type and surgical delay on mortality after surgery for hip fracture. J Bone Joint Surg Br 2005;87:361-6.

18. Moran CG, Wenn RT, Sikand M, Taylor AM. Early mortality after hip fracture: is delay before surgery important? J Bone Joint Surg Am 2005;87:483-9.

19. Orosz GM, Magaziner J, Hannan EL, Morrison RS, Koval K Gilbert M, McLaughlin M, Halm EA, Wang JJ, Litke A, Silberzweig $\mathrm{SB}$, Siu AL. Association of timing of surgery for hip fracture and patient outcomes. Jama 2004;291:1738-43.

20. Aharonoff GB, Koval KJ, Skovron ML, Zuckerman JD. Hip fractures in the elderly: predictors of one year mortality. J Orthop Trauma 1997;11:162-5.

21. Hoenig H, Rubenstein LV, Sloane R, Horner R, Kahn K. What is the role of timing in the surgical and rehabilitative care of community-dwelling older persons with acute hip fracture? Arch Intern Med 1997;157:513-20.

22. Siegmeth AW, Gurusamy K, Parker MJ. Delay to surgery prolongs hospital stay in patients with fractures of the proximal femur. J Bone Joint Surg Br 2005;87:1123-6.

23. Davis TR, Sher JL, Porter BB, Checketts RG. The timing of surgery for intertrochanteric femoral fractures. Injury 1988;19:244-6.

24. Rogers FB, Shackford SR, Keller MS. Early fixation reduces morbidity and mortality in elderly patients with hip fractures from low-impact falls. J Trauma 1995;39:261-5.

25. Zuckerman JD. Hip fracture. N Engl J Med 1996;334:1519-25.
26. Hommel A, Ulander K, Thorngren KG. Improvements in pain relief, handling time and pressure ulcers through internal audits of hip fracture patients. Scand J Caring Sci 2003;17:78-83.

27. Parker MJ, Pryor GA. The timing of surgery for proximal femoral fractures. J Bone Joint Surg Br 1992;74:203-5.

28. Kamel HK, Iqbal MA, Mogallapu R, Maas D, Hoffmann RG. Time to ambulation after hip fracture surgery: relation to hospitalization outcomes. J Gerontol A Biol Sci Med Sci 2003;58:1042-5.

29. Allman RM. Pressure ulcer prevalence, incidence, risk factors, and impact. Clin Geriatr Med 1997;13:421-36.

30. Graves N, Birrell F, Whitby M. Effect of pressure ulcers on length of hospital stay. Infect Control Hosp Epidemiol 2005;26:293-7.

31. Saltzherr TP, Borghans HJ, Bakker RH, Go PM. Proximal femur fractures in the elderly in The Netherlands during the period 1991-2004: incidence, mortality, length of hospital stay and an estimate of the care capacity needed in the future. Ned Tijdschr Geneeskd 2006;150:2599-604.

32. Morrison $M$ (ed). The prevention and treatment of pressure ulcers. Harcourt publishers, London, 2001.

33. Gordon MD, Gottschlich MM, Helvig El, Marvin JA, Richard RL. Review of evidenced-based practice for the prevention of pressure sores in burn patients. J Burn Care Rehabil 2004;25:388-410.

34. Legood R, McInnes E. Pressure ulcers: guideline development and economic modelling. J Adv Nurs 2005;50:307-14.

35. Vrancken Peeters MTFD, Vrancken Peeters MPFM, Merkus JWS, Kastelein GW, Breslau PJ. Decubituspreventie bij patienten met een heupfractuur. Ned Tijdschr Heelkd 2003;12:150-2, 164.

36. Cullum N, McInnes E, Bell-Syer SE, Legood R. Support surfaces for pressure ulcer prevention. Cochrane Database Syst Rev 2004:CDoo1735.

37. Bastow MD, Rawlings J, Allison SP. Benefits of supplementary tube feeding after fractured neck of femur: a randomised controlled trial. Br Med J (Clin Res Ed) 1983;287:1589-92.

38. Eneroth $M$, Olsson UB, Thorngren KG. Nutritional supplementation decreases hip fracture-related complications. Clin Orthop Relat Res 2006.

39. Hanger HC, Smart EJ, Merrilees MJ, Frampton CM. The prevalence of malnutrition in elderly hip fracture patients. N Z Med J 1999;112:88-90.

40. Lumbers M, New SA, Gibson S, Murphy MC. Nutritional status in elderly female hip fracture patients: comparison with an agematched home living group attending day centres. Br J Nutr 2001;85:733-40.

41. Bourdel-Marchasson I, Barateau M, Rondeau V, Dequae-Merchadou L, Salles-Montaudon N, Emeriau JP, Manciet G, Dartigues JF. A multi-center trial of the effects of oral nutritional supplementation in critically ill older inpatients. GAGE group. Groupe aquitain geriatrique d'evaluation. Nutrition 2000;16:1-5.

\section{Address for Correspondence}

Leonard M.F. Rademakers, MD

Department of Cardiothoracic Surgery

Maastricht University Hospital

PO Box 5800

$6202 \mathrm{AZ}$

Maastricht

The Netherlands

Phone (+31/43) 387-5070, Fax -5075

e-mail: I.rademakers@ctc.unimaas.nl 